\title{
Wave energy forecasting using artificial neural networks in the Caspian Sea
}

1 Sanaz Hadadpour MSC Research Assistant, School of Civil Engineering, Iran University of Science and Technology, Tehran, Iran

2. Amir Etemad-Shahidi PhD

Senior Lecturer, Griffith School of Engineering, Gold Coast Campus, Griffith University, Queensland, Australia
3 Bahareh Kamranzad PhD

Assistant Professor, Ocean Engineering and Technology Research Centre, Iranian National Institute for Oceanography and Atmospheric Science, Tehran, Iran
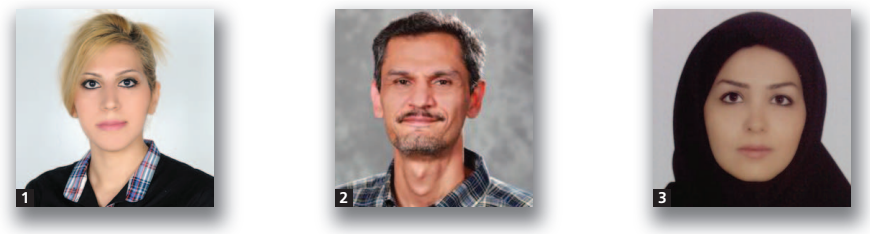

Providing energy without unfavourable impact on the environment is an important issue that is considered by societies. This paper focuses on forecasting the wave energy over horizons of 1-12 $h$, in the southern part of the Caspian Sea. For this purpose, an artificial neural network was used to obtain the wave energy flux using two different methods. First, the components of wave energy flux, including the significant wave height and peak wave period were predicted separately and the wave energy flux was calculated by combining them; and second, the wave energy flux was forecast directly. The results showed that the prediction of components separately yielded more accurate results. It was found that the longer the forecasting time horizon, the less accurate was the prediction. This is because in large time horizons, the previous wave characteristics have little influence on the wave energy flux. The forecast wave energy flux in both methods correlated well with observed data in short horizons.

\section{Notation}

$B$

E

$f$

g

$H$

$N$

$N_{\mathrm{H}}$

$N_{\mathrm{I}}$

$N_{\text {TR }}$

$O$

$\bar{o}$

$o_{i}$

$\bar{p}$

$p_{i}$

$r$

$s_{i} w_{i}$

$T$

$T_{\mathrm{e}}$

$T_{\mathrm{p}}$ bias

wave energy flux of the crest length

function

gravitational acceleration

significant wave height

number of data points

number of neurons in hidden layer

number of inputs

number of training data points

output

mean value of observed data

observed value

mean value of predicted data

predicted value

correlation coefficient

inputs multiplied to their weights

peak wave period

energy period

peak wave period peak enhancement factor

density of seawater

forecasting time horizon (from 1 to $12 \mathrm{~h}$ ) time

\section{Introduction}

One of the most important issues in the world today is to provide energy without having negative impacts on the environment. Traditional means of energy production such as fossil fuels are not clean and their use will diminish in time. Therefore, renewable energy resources are widely considered for this purpose. Renewable energy resources, such as solar, wind, ocean thermal and ocean mechanical energy (i.e. waves, tides and currents) are commonly used in some countries. As renewable energy resources are more expensive than conventional energy sources such as fossil-fuel resources, governments were not interested in these energy resources in the past. Fortunately, this view point has recently changed. For instance, by 2004 in spite of increasing 
utilisation of wind power, the cost of energy transformation from wind power during the previous 30 years had reduced by about 80\% (The National Commission on Energy Policy, 2004).

Wave energy is a renewable energy resource with high power potential and low impact on the environment in coastal regions (Cruz, 2008). The extraction of wave energy depends not only on the type of wave energy converter but also on the location where the converter is deployed. Besides, an important requirement for planning an appropriate wave energy converter and site is the wave energy forecasting. In this study, wave energy forecasting was carried out to obtain the accurate information on the wave energy values for Anzali, an Iranian port on the Caspian Sea.

Generally, wave forecasting methods are classified into two categories: process-based models and statistical techniques. Process-based models are based on theoretical and experimental studies and have been improving since the 1950s (Miles, 1957; Phillips, 1957, 1958). Recent advances in this field include the introduction of the third-generation (3G) models, such as WAM (WAve Modelling) used for wave modelling in deep-water areas (Komen et al., 1994), and SWAN (Simulating WAves Nearshore) for high-resolution grids to achieve economical modelling results in coastal areas (Booij et al., 1999; Moeini et al., 2010).

Statistical techniques have been developed recently. Artificial neural networks (ANNs) are one of the most commonly used approaches (Asma et al., 2012; Deo and Naidu, 1998; Deo and Jagdale, 2003; Deo et al., 2001; Jain and Deo, 2007; Londhe and Panchang, 2006; Makarynskyy, 2004; Mase et al., 2007; Ozger, 2010; Tsai et al., 2002; Tseng et al., 2007; Zamani et al., 2008). Regression-based models have also been used by many researchers such as Malmberg et al. (2005), Ho and Yim (2006) and Roulston et al. (2005). Genetic programming has also been used by Gaur and Deo (2008). Several investigators have also combined both methods by statistical post-processing of physics-based model forecasts (Durrant et al., 2008; Woodcock and Engel, 2005; Woodcock and Greenslade, 2006).

The ANN has been used widely in ocean engineering (Mase, 1995; Mase et al., 1995, 2001). Mase et al. (2011) evaluated the ANN for prediction of tsunami water level. They used different tsunami conditions for training the ANN, and then forecast the preliminary and secondary tsunami waves which agreed well with the numerical results of tsunami simulation. Furthermore, there are many studies in which ANN has been used to forecast the wave parameters. Several research studies have used ANN to forecast wave parameters such as significant wave height and wave energy flux.

Mandal and Prabaharan (2010) showed that ANN predicts wave parameters successfully, and the predicted values are very close to the observed values in short lead times. Rao and
Mandal (2005) used the neural network approach to estimate the wave heights and periods and found the estimated wave parameters match well with those hindcasted using Young's model (the parametric hurricane wave prediction model by Young (1988)). Makarynskyy et al. (2005) used two different neural network strategies to forecast significant wave heights and zero-up-crossing wave periods, and showed the suitability of the artificial neural technique for short-term forecasts of the wave parameters. Asma et al. (2012) employed multiple linear regression (MLR) and ANN models for prediction of the significant wave height and found that ANN provides smaller MSE for prediction of this parameter.

Reikard (2009) used data sets from four Pacific Ocean sites to evaluate the ability of time-series models for forecasting ocean wave energy. It was found that over horizons of 1 to $4 \mathrm{~h}$, forecasting the components separately using time-varying regressions yields the best results. In addition, in daily data sets over 1-3 days, the hybrid model, a combined neural network with a time-varying regression and a regression model, yielded similar results.

Reikard et al. (2011) predicted the significant wave height, peak wave period and wave energy flux. For this purpose, 13 data sets from the Atlantic and Pacific Oceans and the Gulf of Mexico were used. They compared a physics-based model, the European Centre for Medium-Range Weather Forecasts (ECMWF) wave model, with two statistical techniques, timevarying parameter regressions and neural networks. They found that at short horizons from 1 to $5 \mathrm{~h}$, the statistical models are more accurate than ECMWF, whereas at longer horizons the ECMWF model performed better. Moreover, they used the forecasts from the ECMWF model as inputs in regressions and neural networks, and showed that the combined models are more accurate than the individual ones.

The Caspian Sea is an important enclosed sea, which is surrounded by vast coastal areas (Figure 1) and can provide clean wave energy. The wave energy flux has not been investigated in this sea yet. Therefore, in this study, ANN is used to forecast the wave energy for horizons of 1 to 6,9 and $12 \mathrm{~h}$ by using buoy measurements in Anzali in the southwestern part of the Caspian Sea. Section 2 presents the study area and the location of Anzali buoy. Section 3 consists of an overview of the databases. Results are reported in Section 4 and conclusions are drawn in Section 5.

\section{Study area and evaluation of the data}

In the present study, the wave energy was forecast in the southwestern part of the Caspian Sea, at Anzali port. Figure 1 shows the location of Anzali buoy. The Caspian Sea is the largest enclosed basin in the world and is surrounded by five countries; Iran, Turkmenistan, Kazakhstan, Russia and Azerbaijan. 


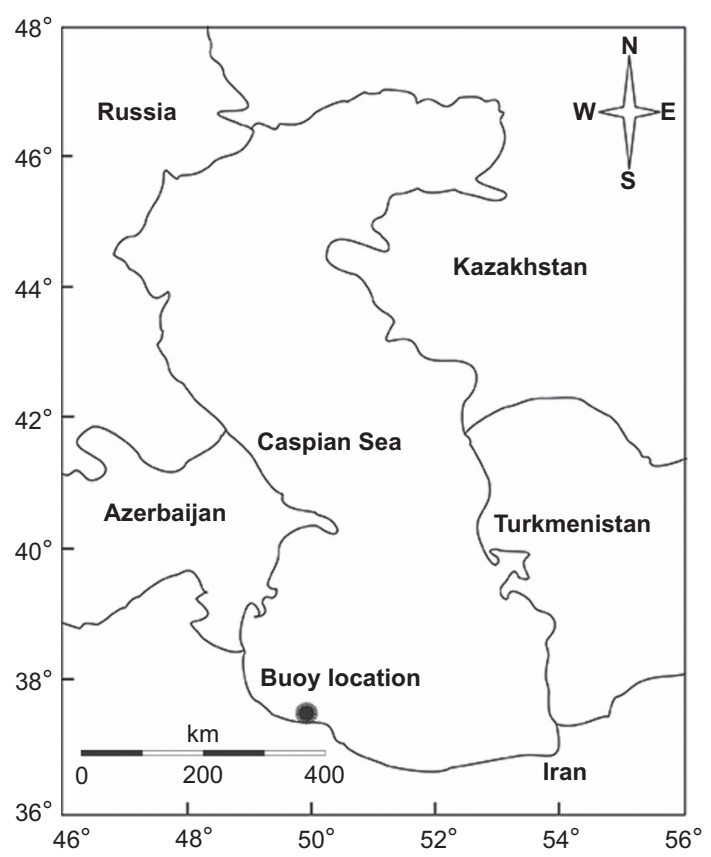

Figure 1. Caspian Sea and the location of Anzali buoy

Important economic activities in the Caspian Sea, including fisheries, agriculture, rich resources of oil and gas, and the possibility of transportation between Europe and Asia have made this sea vital.

The wave data were measured by the Anzali buoy, which was deployed by Guilan Meteorological Organisation in Iran. The Anzali buoy was located at $49 \cdot 89^{\circ} \mathrm{E}$ and $37 \cdot 49^{\circ} \mathrm{N}$. The water depth at this location was about $20 \mathrm{~m}$. The period of data collection was from 1 March 2010 to 10 May 2011. The wave data, consisting of significant wave height and peak wave period, were recorded at $1 \mathrm{~h}$ intervals. The wave energy flux obtained from these values is calculated as (Abbaspour and Rahimi, 2011; Kamranzad et al., 2013)

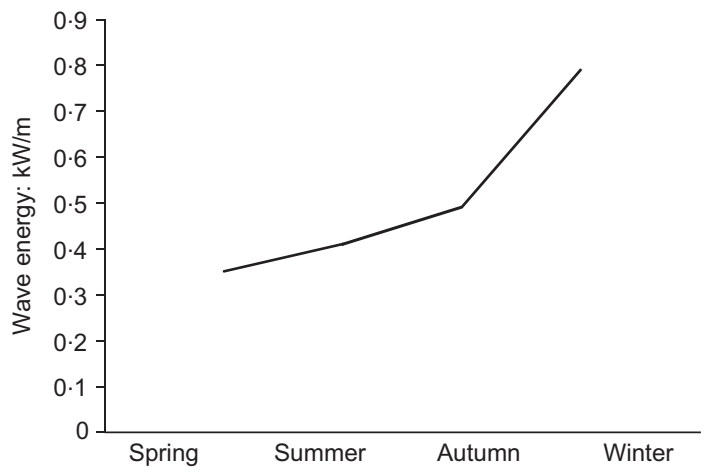

Figure 2. Seasonal variation of wave energy

1. $E=\left[\left(\boldsymbol{g}^{2} \rho / 64 \pi\right) H^{2} T_{\mathrm{e}} / 1000 \approx 0 \cdot 491\left(H^{2} T_{\mathrm{e}}\right)\right]$

where $E$ is the wave energy flux of the crest length $(\mathrm{kW} / \mathrm{m})$, $\boldsymbol{g}$ is the gravitational acceleration $\left(9 \cdot 81 \mathrm{~m} / \mathrm{s}^{2}\right), \rho$ is the density of seawater $\left(1025 \mathrm{~kg} / \mathrm{m}^{3}\right), H$ is the significant wave height (m) and $T_{\mathrm{e}}$ is the wave energy period (s). When the peak wave period $\left(T_{\mathrm{p}}\right)$ is available, $T_{\mathrm{e}}$ is equal to $T_{\mathrm{p}}$ multiplied by a factor of 0.9 if the standard Joint North Sea Wave Project spectrum with a peak enhancement factor of $\gamma=0.33$ is assumed (Abbaspour and Rahimi, 2011; Saket and EtemadShahidi, 2012).

The continuous hourly data set from 1 March 2010 to 5 December 2010 was used for training the networks and the continuous hourly data set from 22 December 2010 to 10 May 2011 was used for testing the networks. Statistics of the wave parameters for two different sets of data (training and testing) are illustrated in Table 1. In addition, the seasonal average of the observed wave energy (i.e. obtained from observed wave parameters using Equation 1) is illustrated in Figure 2. According to this figure, the average wave energy increases from spring to autumn and then there is a sharp increase from autumn to winter. Moreover, the peak seasonal wave energy is observed in winter, due to the stronger winds that blow in this season.

\begin{tabular}{|c|c|c|c|c|}
\hline Parameter & Stage & Minimum & Average & Maximum \\
\hline & Training & $0 \cdot 1$ & $0 \cdot 402$ & $2 \cdot 5$ \\
\hline \multirow[t]{2}{*}{ Significant wave height: $\mathrm{m}$} & Testing & $0 \cdot 1$ & 0.529 & $2 \cdot 3$ \\
\hline & Training & $1 \cdot 7$ & $2 \cdot 465$ & $10 \cdot 3$ \\
\hline \multirow[t]{2}{*}{ Peak wave period: s } & Testing & $1 \cdot 7$ & $2 \cdot 568$ & $4 \cdot 4$ \\
\hline & Training & 0.008 & $0 \cdot 44$ & $12 \cdot 889$ \\
\hline Wave energy: $\mathrm{kW} / \mathrm{m}$ & Testing & 0.008 & 0.66 & $9 \cdot 87$ \\
\hline
\end{tabular}

Table 1. Statistics of the wave parameters in different data sets used for training and testing 


\section{Forecasting test (ANN) and performed models}

ANN is a computing technique widely applied in recent years and it works similarly to the biological neurons of the human brain. The ANN structure includes some layers; the input layer and the output layer consist of the number of neurons equal to the number of input and output parameters, respectively. The so-called hidden layer is between the input and output layers. ANN connects every input to the corresponding output through the hidden layer and finds the relationship between the input and the output. The number of neurons in the hidden layer can be selected by using trial and error, and then the selected hidden nodes can be checked based on the following criteria presented by Hecht-Nielson (1987) and Rogers and Dowla (1994)

2. $N_{\mathrm{H}}<2 N_{\mathrm{I}}+1$

\section{3. $N_{\mathrm{H}}<N_{\mathrm{TR}} /\left(N_{\mathrm{I}}+1\right)$}

where $N_{\mathrm{H}}$ denotes the number of neurons in hidden layer, $N_{\mathrm{I}}$ denotes the number of inputs and $N_{\mathrm{TR}}$ denotes the number of training data points.

ANN uses the self-learning technique and returns the pattern to achieve relevant output from input without any fixed mathematical formula (Jain and Deo, 2006; Mandal and Prabaharan, 2006). In order to use ANN for prediction purposes, a network should be initially trained to determine the proper set of the weights to achieve the minimum error for the modelling results. The output neurons are created by applying the transfer function to the inputs. Within the training, by comparing the predicted and observed data, biases and weights are allowed to alter at each point until the required accuracy is achieved.

In this study, the significant wave height and the peak wave period were used as inputs and the outputs were obtained using two different methods. In the first approach, the components of the wave energy, namely the significant wave height and the peak wave period, were forecast separately and in the second approach, the wave energy flux was forecast directly. The output layer consists of one neuron (significant wave height, peak wave period or wave energy flux) and the number of iterations was 1000 . Our preliminary modelling showed that even though it is possible to have ANN models with three outputs, the accuracy generally decreases due to the complexity of the network. This finding is in line with the existing knowledge about the performance of ANN networks (Asma et al., 2012; Kamranzad et al., 2011; Zamani et al., 2008).

In several investigations, $80 \%$ of available data were used for the training and the remaining 20\% were used for testing (Agrawal and Deo, 2002; Deo et al., 2001; Kamranzad et al., 2011; Mandal and Prabaharan, 2006). An important requirement that should be considered for dividing the data into different sets for training and testing models is the relative statistical similarity in both datasets. In this study, two-thirds of data were used for training the models and the rest of the data were selected for testing the models.

Jain and Deo (2006), Erdil and Arcaklioglu (2012) and Jain and Deo (2008) applied the most popular network, the feed forward network and training algorithm combination with the standard back propagation algorithm. In this paper, a feed forward-conjugate gradient network with a non-linear sigmoid transfer function and five neurons in the hidden layer is used. The sigmoid transfer function is shown by

4. $O=1 /\left[1+\mathrm{e}^{-X}\right]$

5. $X=\left(s_{1} w_{1}+s_{2} w_{2}+s_{3} w_{3}+\ldots\right)+B$

where $O$ denotes the output, $s_{i} w_{i}$ denotes the inputs multiplied to their weights and $B$ indicates the bias.

In addition to these two approaches for wave energy flux forecasting, different models can be used to forecast the wave characteristics directly. In order to find the most important input parameters and to improve the accuracy, various combinations of the wave characteristics were tested as input parameters. These models are as follows

6. Model A : $H_{t+i}=f\left(H_{t}, H_{t-1}, H_{t-2}\right)$

7. Model B : $T_{t+i}=f\left(T_{t}, T_{t-1}, T_{t-2}\right)$

8. Model C : $H_{t+i}=f\left(H_{t}, H_{t-1}, H_{t-2}, T_{t}, T_{t-1}, T_{t-2}\right)$

9. Model D : $H_{t+i}^{2}=f\left(H_{t}^{2}, H_{t-1}^{2}, H_{t-2}^{2}, T_{t}, T_{t-1}, T_{t-2}\right)$

10. Model E : $T_{t+i}=f\left(H_{t}, H_{t-1}, H_{t-2}, T_{t}, T_{t-1}, T_{t-2}\right)$

11. Model $\mathrm{F}: E_{t+i}=f\left(H_{t}, H_{t-1}, H_{t-2}, T_{t}, T_{t-1}, T_{t-2}\right)$ 


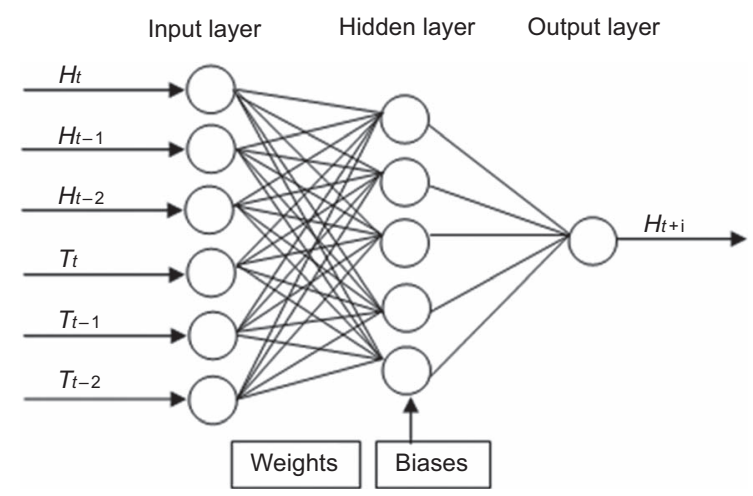

Figure 3. Structure of the ANN for model C

12. Model G : $E_{t+i}=f\left(H_{t}^{2}, H_{t-1}^{2}, H_{t-2}^{2}, T_{t}, T_{t-1}, T_{t-2}\right)$

where $i$ is the forecasting time horizon (from 1 to $12 \mathrm{~h}$ ). The lag time was selected based on testing different lag times.

Models $\mathrm{A}$ and $\mathrm{C}$ were used to forecast the significant wave height, and model D was used to forecast the significant wave height squared. Moreover, models $\mathrm{B}$ and $\mathrm{E}$ were used to forecast the peak wave period. Different combinations of these forecasts were used to calculate the wave energy flux. In addition, model $\mathrm{AB}$ was developed from combining models $\mathrm{A}$ and $\mathrm{B}$. In the same way, models $\mathrm{CB}, \mathrm{CE}$ and $\mathrm{DB}$ were developed from combining models $\mathrm{C}$ and $\mathrm{B}, \mathrm{C}$ and $\mathrm{E}$ and $\mathrm{D}$ and $\mathrm{B}$, respectively. These models are given by

13. Model $\mathrm{AB}=0 \cdot 491 \times(\text { Model } \mathrm{A})^{2} \times($ Model $\mathrm{B})$

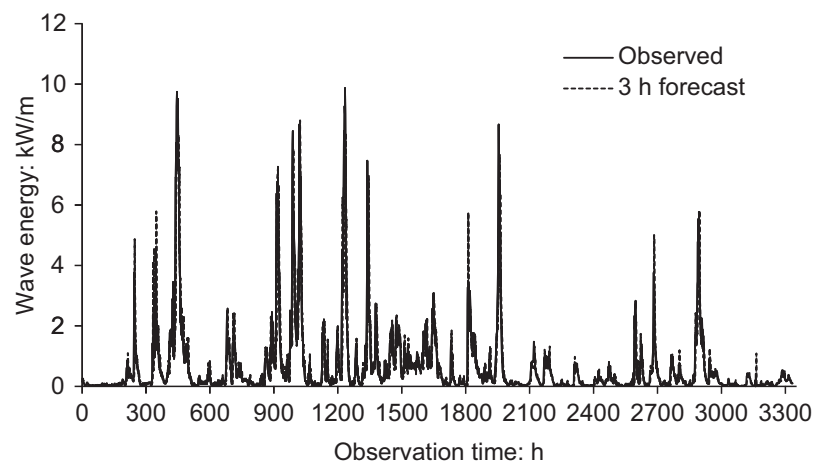

Figure 4. Forecast wave energy flux using model $\mathrm{CE}, 3 \mathrm{~h}$ forecasting

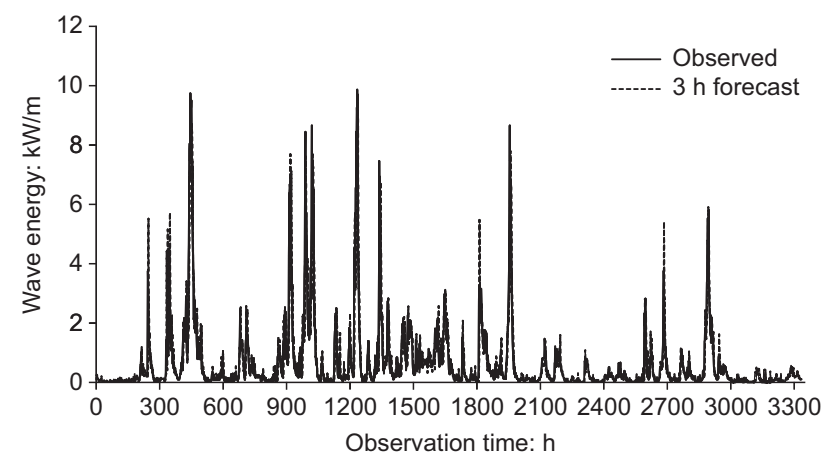

Figure 5. Forecast wave energy flux using model F, $3 \mathrm{~h}$ forecasting

14. Model $\mathrm{CB}=0 \cdot 491 \times(\text { Model } \mathrm{C})^{2} \times($ Model $\mathrm{B})$

15. Model CE $=0 \cdot 491 \times(\text { Model } C)^{2} \times($ Model E $)$

\section{Model $\mathrm{DB}=0 \cdot 491 \times($ Model $\mathrm{D}) \times($ Model $\mathrm{B})$}

In brief, models $\mathrm{A}$ to $\mathrm{E}$ were used to forecast the components separately, and models $F$ and $G$ were used for direct forecasting of the wave energy flux. Figure 3 shows the network architecture of model $\mathrm{C}$ with three layers (input, hidden and output), six inputs $\left(H_{t}, H_{t-1}, H_{t-2}, T_{t}, T_{t-1}, T_{t-2}\right)$ and one output (wave height at the next ' $i$ ' hours).

\section{Results and discussion}

The forecasting was performed over horizons of 1 to 6,9 and $12 \mathrm{~h}$. First, the components of the wave energy flux, including the significant wave height and peak wave period were forecast

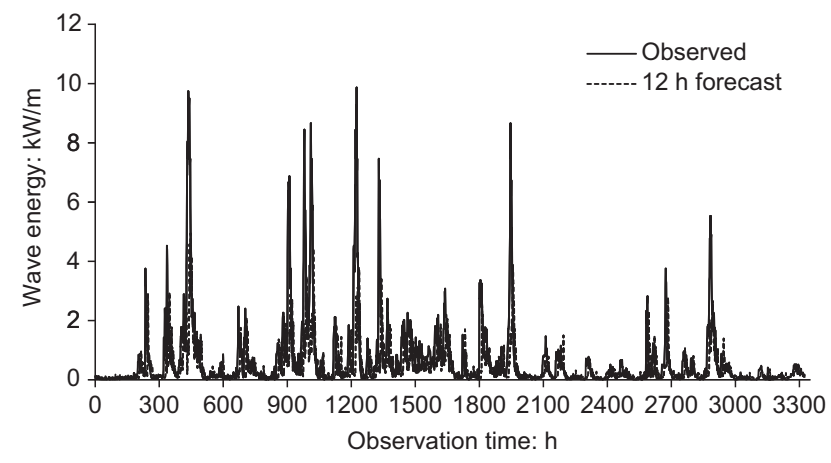

Figure 6. Forecast wave energy flux using model CE, $12 \mathrm{~h}$ forecasting 


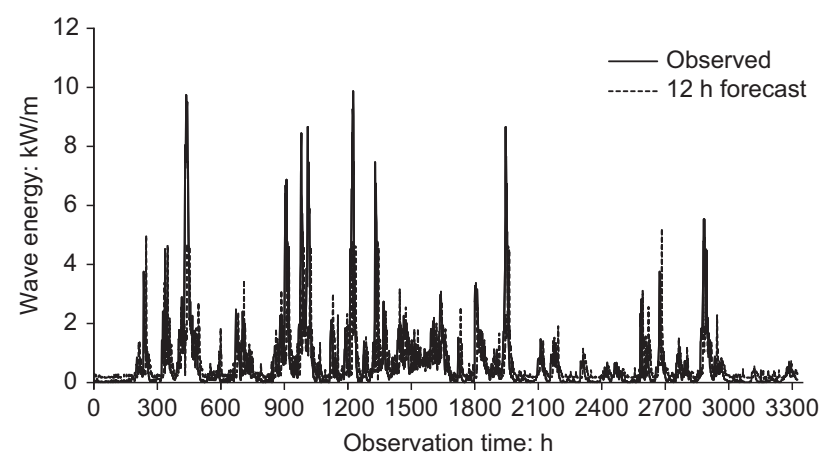

Figure 7. Forecast wave energy flux using model $\mathrm{G}, 12 \mathrm{~h}$ forecasting

separately, and the wave energy flux was calculated by combining the results. In the second approach, the wave energy flux was forecast directly.

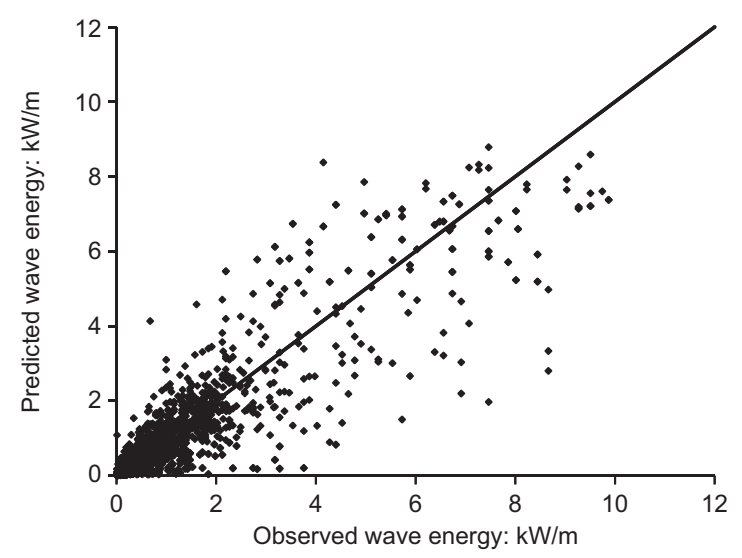

(a)

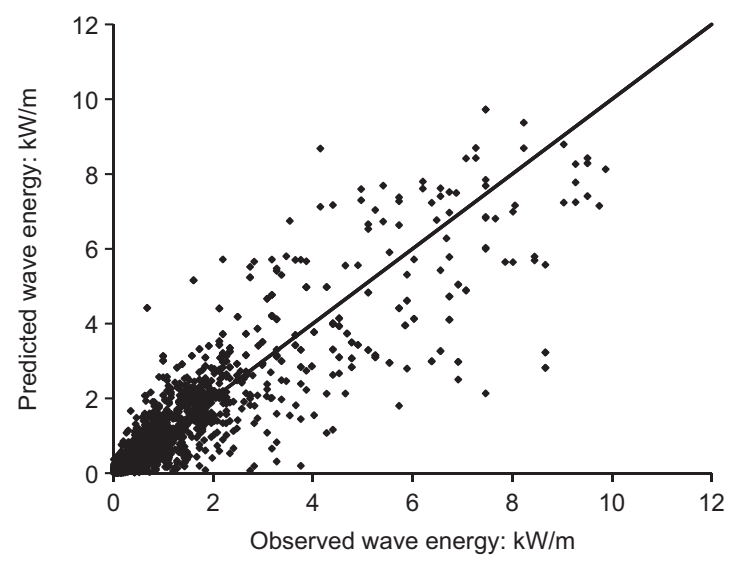

(b)

Figure 8. Scatter diagram for 3 hourly forecast: (a) using model CE; (b) using model F

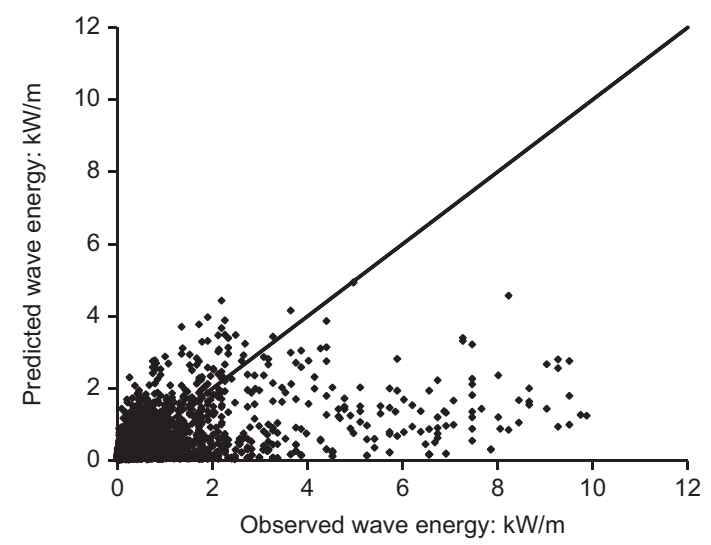

(a)

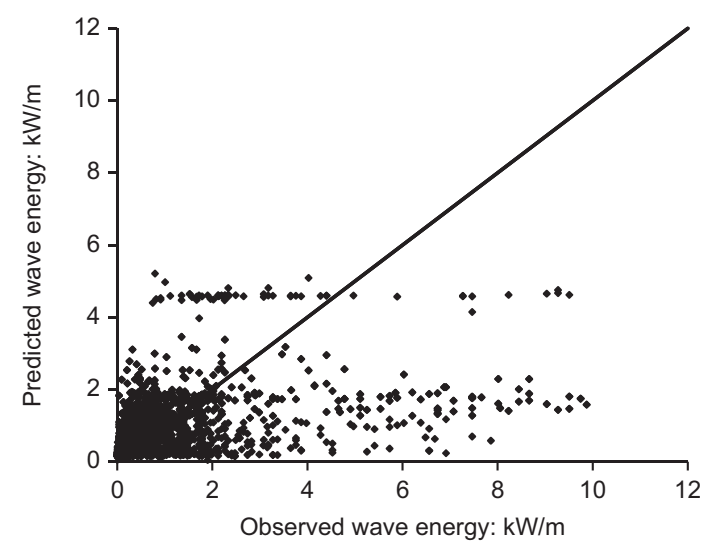

(b)

Figure 9. Scatter diagram for 12 hourly forecast: (a) using model CE; (b) using model G

Figures 4 to 7 illustrate the time series for 3 and $12 \mathrm{~h}$ forecasting. Figures 4 and 5 show the time series of the observed wave energy (i.e. obtained from observed wave parameters using Equation 1) and 3 hourly forecast wave energy flux for model CE and model F, respectively. Figure 4 shows that for short time horizons, the forecast wave energy flux for model CE correlated well with the observed values. Comparison of Figures 4 and 5 represents similar results and correlation between the observed and forecast wave energy flux for short time horizons for both methods.

Figures 6 and 7 show the time series of the observed and 12 hourly forecast wave energy flux for model CE and model G, respectively. According to these figures, when the forecasting horizon increased to $12 \mathrm{~h}$, the difference between the observed and forecast wave energy flux increased and both methods underestimated, especially in extreme events. Therefore, it can be concluded that as the forecasting time horizon increases, the ability of ANN for the prediction of wave energy flux 


\begin{tabular}{|c|c|c|c|c|c|}
\hline Error index & Forecast horizon & Model AB & Model CB & Model CE & Model DB \\
\hline \multirow[t]{8}{*}{$r$} & 1 & 0.975 & 0.976 & 0.976 & 0.976 \\
\hline & 2 & 0.947 & 0.947 & 0.946 & 0.946 \\
\hline & 3 & 0.904 & 0.907 & 0.905 & 0.905 \\
\hline & 4 & $0 \cdot 866$ & $0 \cdot 866$ & $0 \cdot 867$ & $0 \cdot 866$ \\
\hline & 5 & $0 \cdot 824$ & $0 \cdot 828$ & $0 \cdot 829$ & $0 \cdot 828$ \\
\hline & 6 & $0 \cdot 773$ & $0 \cdot 779$ & $0 \cdot 780$ & $0 \cdot 774$ \\
\hline & 9 & 0.630 & 0.645 & 0.646 & 0.628 \\
\hline & 12 & $0 \cdot 512$ & 0.529 & 0.533 & $0 \cdot 531$ \\
\hline \multirow{8}{*}{$\begin{array}{l}\text { Mean absolute } \\
\text { percentage error }\end{array}$} & 1 & $0 \cdot 114$ & $0 \cdot 117$ & $0 \cdot 117$ & $0 \cdot 139$ \\
\hline & 2 & $0 \cdot 169$ & $0 \cdot 172$ & $0 \cdot 172$ & $0 \cdot 189$ \\
\hline & 3 & $0 \cdot 210$ & $0 \cdot 209$ & $0 \cdot 209$ & $0 \cdot 244$ \\
\hline & 4 & $0 \cdot 242$ & $0 \cdot 242$ & $0 \cdot 242$ & $0 \cdot 274$ \\
\hline & 5 & $0 \cdot 271$ & $0 \cdot 269$ & $0 \cdot 271$ & $0 \cdot 295$ \\
\hline & 6 & $0 \cdot 296$ & 0.295 & $0 \cdot 295$ & $0 \cdot 328$ \\
\hline & 9 & $0 \cdot 363$ & $0 \cdot 360$ & $0 \cdot 361$ & $0 \cdot 397$ \\
\hline & 12 & $0 \cdot 412$ & 0.408 & 0.408 & 0.448 \\
\hline
\end{tabular}

Table 2. Error indices of the wave energy flux obtained from the combination of the separately forecast components, 1 to 12 hourly forecasts

decreases, especially in extreme events. As the ANN network was trained with data in which moderate waves prevailed overwhelmingly, it slightly underpredicted extreme waves.

The scatter diagrams of observed and predicted wave energies are presented in Figures 8 and 9 for 3 and 12 hourly forecasts, respectively. It can be seen from the distribution of the results around the $45^{\circ}$ exact fit line that there is a good agreement between the observed and predicted values for $3 \mathrm{~h}$ forecasting. However, for $12 \mathrm{~h}$ forecasting ANN underestimated the wave energy especially, in extreme events.

In order to evaluate the models' performance quantitatively and find the best model, error indices were compared. In the present study, the mean absolute percentage error and the correlation coefficient $(r)$ were used

mean absolute percentage error(Reikard, 2009)

17. $=\frac{\sum_{i=1}^{N}\left|\log p_{i}-\log o_{i}\right|}{N}$

18. $r=\frac{\sum_{i=1}^{N}\left[\left(o_{i}-\bar{o}\right) \times\left(p_{i}-\bar{p}\right)\right]}{\sqrt{\sum_{i=1}^{N}\left(o_{i}-\bar{o}\right)^{2} \sum_{i=1}^{N}\left(p_{i}-\bar{p}\right)^{2}}}$

where $o_{i}$ denotes the observed value, $\bar{o}$ denotes the mean value of observed data, $p_{i}$ is the predicted value, $\bar{p}$ is the mean value of predicted data and $N$ is the number of data points.
Table 2 shows the error indices, namely the mean absolute percentage error and the parameter $r$ for the wave energy flux, obtained from different combinations of forecast wave characteristics.

The average errors for the wave energy flux were from 11 to $41 \%$ for model AB, 12 to $41 \%$ for models $\mathrm{CB}$ and $\mathrm{CE}$ and 14 to $45 \%$ for model DB. For all models, as forecasting time increased, the mean absolute percentage error increased and the correlation coefficient decreased. It can be concluded that the ability of the prediction models decreases when the forecasting time horizon increases. This is due to the fact that dependence of the wave energy flux on the previous wave characteristics decreases in a large time horizon. Kamranzad et al. (2011) showed that the correlation between the predicted and the previous wave heights decreases as the lead time increases from 3 to $24 \mathrm{~h}$. As the wave energy flux is proportional to the square of wave height it can be found that the correlation between the wave energy flux and the previous wave parameters decreases as the forecasting horizon increases (i.e. there is a non-linear increase in the average error for the wave energy flux, so it increases smoothly from 11 for $1 \mathrm{~h}$ forecasting to $41 \%$ for $12 \mathrm{~h}$ forecasting).

The comparison of the parameter $r$ and the average error indicates that model $\mathrm{CB}$ was more accurate than model $\mathrm{AB}$. For the wave energy flux, although the parameter $r$ from model $\mathrm{DB}$ is nearly the same as that of models $\mathrm{CB}$ and $\mathrm{AB}$, the average error for model DB is about $3 \%$ larger than models $\mathrm{CB}$ 


\begin{tabular}{lccc} 
Error index & Forecast horizon & Model F & Model G \\
\hline$r$ & 3 & 0.906 & 0.903 \\
& 6 & 0.767 & 0.763 \\
& 9 & 0.639 & 0.651 \\
Mean absolute percentage error & 12 & 0.495 & 0.516 \\
& 3 & 0.243 & 0.242 \\
& 6 & 0.348 & 0.464 \\
& 9 & 0.496 & 0.427
\end{tabular}

Table 3. Error indices of direct forecasting of wave energy

and $\mathrm{AB}$. This means that forecasting of significant wave height as a component to forecast the wave energy flux yields more accurate results than prediction of the square of significant wave height. Furthermore, the results show that the average error and the parameter $r$ for the wave energy obtained from model CE is nearly the same as that of model CB. This is because in both approaches the significant wave height was obtained from the same model (i.e. model C) and, as considered before, wave energy flux is proportional to the square of significant wave height. Finally, it can be concluded that the prediction of the wave energy flux using the models CE and $\mathrm{CB}$, among the other models, yielded more accurate results.

Another method is to use ANN for forecasting of the wave energy flux directly. For this purpose, models $F$ and $G$ were used for direct forecasting of the wave energy flux at horizons of 3, 6, 9 and $12 \mathrm{~h}$. Table 3 shows the error indices for direct forecasting of the wave energy flux. The average errors for the wave energy flux are 24 to $49 \cdot 6 \%$ for both models $\mathrm{F}$ and $\mathrm{G}$ for different time horizons.

It was found that, similar to the previous approach, the model performance decreases as the forecasting time horizon increases for direct forecasting of the wave energy flux (e.g. Kamranzad et al., 2011; Reikard, 2009; Reikard and Rogers, 2011). The results show that the average error was slightly lower and the parameter $r$ was higher for model $\mathrm{F}$ than those obtained from model $\mathrm{G}$ up to $6 \mathrm{~h}$ forecasting. At longer time horizons, the average error for model $\mathrm{G}$ was slightly lower and the parameter $r$ was higher than those of model F. This means that for direct forecasting of the wave energy flux, models $F$ and $\mathrm{G}$ produce more accurate results for short-term horizon and large time horizon, respectively. This is due to the fact that different inputs are influential in different forecasting time horizons and selecting the most appropriate parameters as inputs produce more accurate results. This result is similar to wave height forecasting in which the wind characteristics are more influential in large lead times. However, the forecast wave height and the previous wave heights are correlated well up to 6 h (Kamranzad et al., 2011).

The comparison between the wave energy flux from model CE and model $\mathrm{F}$ and also from model DB and model $\mathrm{G}$ (i.e. the comparison of the models in which the same combinations of parameters as inputs were used) is shown in Table 4. This table represents the improvement in accuracy for the mean absolute percentage error when forecasting the components separately, compared to the direct forecast of the wave energy flux.

The results show that the improvement in accuracy of results is more considerable at all horizons for model CE than other models. This improvement for the mean absolute percentage error was $14 \%$ for $3 \mathrm{~h}$ forecasting and increased to $17 \cdot 7 \%$ for $12 \mathrm{~h}$ forecasting. Generally, the results demonstrate that

\begin{tabular}{lcr}
\hline Forecast horizon: $h$ & Model CE relative to model F: \% & Model DB relative to model G: \% \\
\hline 3 & $13 \cdot 99$ & $-0 \cdot 83$ \\
6 & $15 \cdot 23$ & $9 \cdot 89$ \\
9 & $16 \cdot 44$ & $7 \cdot 03$ \\
12 & $17 \cdot 74$ & $9 \cdot 49$
\end{tabular}

Table 4. Relative improvement for the mean absolute percentage error of forecasting the wave energy flux components separately 


\begin{tabular}{lcll} 
Reference & Hour & Error & Method \\
\hline Reikard (2009) & 1 & $0 \cdot 255$ & Components forecast separately \\
& 2 & $0 \cdot 305$ & \\
Reikard et al· (2011) & 3 & $0 \cdot 343$ & Neural network \\
& 6 & $0 \cdot 3$ & \\
& 9 & $0 \cdot 475$ &
\end{tabular}

Table 5. Comparison of the mean absolute percentage error for forecasting the wave energy flux

forecasting the wave energy from separate predicted components yields more accurate results than direct forecast of the wave energy flux.

The results of this study were compared with those of Reikard (2009) and Reikard et al. (2011) (Table 5). This study gave results that were 54, 43.7 and $39 \%$ better for 1,2 and $3 \mathrm{~h}$ forecasts, respectively, compared to Reikard (2009) Kauai forecasts using two components of wave energy separately (Reikard's best model). The results of Reikard et al. (2011) presented for the prediction of the wave energy flux using neural network for the average of 13 sites were also investigated. The relative improvements in this study were $1 \cdot 7,7 \cdot 9$ and $14 \cdot 1 \%$ for 6,9 and $12 \mathrm{~h}$, respectively. Hence these results, which are more accurate than Reikard (2009) and Reikard et al. (2011), are considered satisfactory.

Furthermore, an important issue is that the actual power output from wave energy converters (WECs) is not equal to the flux. Babarit et al. (2012) investigated eight wave energy converters at five locations. They estimated the power matrices per sea state and the annual absorbed wave energy for each WEC, at different locations. Their methodology to obtain power matrices, which are specified as a function of the significant wave height and peak period, can also be used to estimate the power output in Anzali.

\section{Summary and conclusion}

In this study, ANN was used for forecasting the wave energy flux over horizons of 1 to $12 \mathrm{~h}$ in Anzali port, the Caspian Sea. For this purpose, a feed-forward-conjugate gradient network with sigmoid transfer function and one hidden layer consisting of five neurons was used. Forecasting of wave energy flux was carried out using two different approaches. First, the wave energy flux was calculated from the separately predicted components (i.e. significant wave height and peak wave period). Second, the wave energy flux was directly predicted. In order to evaluate the different parameters for estimating the best result for each model, various combinations of the wave characteristics were investigated as inputs. Furthermore, different models with varying lag times were tested and the best results were obtained by using a lag time of $3 \mathrm{~h}$ (e.g. the average errors for the wave energy flux were about $11 \%$ for $1 \mathrm{~h}$ forecasting).

The results show that increasing the forecasting time horizons leads to a decrease of the predictive accuracy (e.g. the average error for the wave energy flux was $11 \%$ for $1 \mathrm{~h}$ forecasting, which increased to $41 \%$ for $12 \mathrm{~h}$ forecasting for model AB). Moreover, in spite of the correlation between time series of the forecast and observed wave energy flux for both methods, forecasting the separate components performed better than direct forecast of the wave energy flux. Furthermore, it was found that forecasting the significant wave height as a component of wave energy improved the accuracy of results in comparison with forecasting the square of significant wave height. In addition, the results showed that wave energy obtained from models CE and CB leads to lower error and higher correlation in comparison with the other models. This means that the models $\mathrm{CE}$ and $\mathrm{CB}$ are more appropriate than the other models for forecasting the wave energy flux for this location.

\section{Acknowledgements}

The authors are grateful to Guilan Meteorological Organisation for providing wave data. They also thank Lisham Bonakdar for editing the manuscript and Pedram Ghaderi for his helpful comments. This study was partly supported by the Deputy of Research, Iran University of Science and Technology.

\section{REFERENCES}

Abbaspour M and Rahimi R (2011) Iran atlas of offshore renewable energies. Journal of Renewable Energy 36(1): 388-398.

Agrawal JD and Deo MC (2002) On-line wave prediction. Journal of Marine Structures 15(1): 57-74.

Asma S, Sezer A and Ozdemir O (2012) MLR and ANN models of significant wave height on the west coast of India. Journal of Computers and Geosciences 49: 231-237.

Babarit A, Hals J, Muliawan MJ et al. (2012) Numerical benchmarking study of a selection of wave energy converters. Journal of Renewable Energy 41(1): 44-63. 
Booij N, Ris RC and Holthuijsen LH (1999) A third-generation wave model for coastal regions. 1. Model description and validation. Journal of Geophysical Research 104(C4): 7649-7666.

Cruz J (2008) Ocean Wave Energy. Springer, Heidelberg, Germany.

Deo MC and Jagdale SS (2003) Prediction of breaking waves with neural networks. Journal of Ocean Engineering 30(9): 1163-1178.

Deo MC, Jha A, Chaphekar AS and Ravikant K (2001) Neural networks for wave forecasting. Journal of Ocean Engineering 28(7): 889-898.

Deo MC and Naidu CS (1998) Real time wave forecasting using neural networks. Journal of Ocean Engineering 26(3): 191203.

Durrant TH, Woodcock F and Greenslade DJM (2008) Consensus forecasts of modeled wave parameters. Journal of Weather Forecasting 24(2): 492-503.

Erdil A and Arcaklioglu E (2012) The prediction of meteorological variables using artificial neural network. Neural Computing and Applications 22(7-8): 1677-1683.

Gaur S and Deo MC (2008) Real-time wave forecasting using genetic programming. Journal of Ocean Engineering 35(1112): $1166-1172$.

Hecht-Nielson R (1987) Kolmogorov's mapping neural network existence theorem. In Proceedings of the First IEEE International Joint Conference on Neural Networks, Vol 3, New York, NY, USA, pp. 11-14.

Ho PC and Yim JZ (2006) Wave height forecasting by the transfer function model. Journal of Ocean Engineering 33(8): 1230-1248.

Jain P and Deo MC (2006) Neural networks in ocean engineering. Journal of Ships and Offshore Structures 1(1): 25-35.

Jain P and Deo MC (2007) Real-time wave forecasts off the western Indian coast. Journal of Applied Ocean Research 29(2): 72-79.

Jain P and Deo MC (2008) Artificial intelligence tools to forecast ocean waves in real time. The Open Ocean Engineering Journal 1(1): 13-20.

Kamranzad B, Etemad-Shahidi A and Kazeminezhad MH (2011) Wave height forecasting in Dayyer, the Persian Gulf. Journal of Ocean Engineering 38(1): 248-255.

Kamranzad B, Chegini V and Etemad-Shahidi A (2013) Assessment of wave energy variation in the Persian Gulf. Journal of Ocean Engineering 70(9): 72-80.

Komen GJ, Cavaleri L, Donelan M et al. (1994) Dynamics and Modeling of Ocean Waves. Cambridge University Press, Cambridge, UK.

Londhe SN and Panchang V (2006) One-day wave forecasts based on artificial neural networks. Journal of Atmospheric and Oceanic Technology 23(11): 1593-1603.

Makarynskyy O (2004) Improving wave predictions with artificial neural networks. Journal of Ocean Engineering 31(5): 709-724.
Makarynskyy O, Pires-Silva AA, Makarynska D and VenturaSoares C (2005) Artificial neural networks in wave predictions at the west coast of Portugal. Journal of Computers and Geosciences 31(4): 415-424.

Malmberg A, Holst U and Holst J (2005) Forecasting nearsurface ocean winds with Kalman filter techniques. Journal of Ocean Engineering 32(3): 273-291.

Mandal S and Prabaharan N (2006) Ocean wave forecasting using recurrent neural networks. Journal of Ocean Engineering 33(10): 1401-1410.

Mandal S and Prabaharan N (2010) Ocean wave prediction using numerical and neural network models. The Open Ocean Engineering Journal 3: 12-17.

Mase H (1995) Evaluation of artificial armour layer stability by neural network method. In Proceedings of the 26th Congress of IAHR, London, UK, pp. 341-346.

Mase H, Reis MT, Nagahashi S, Saitoh T and Hedges TS (2007) Effects of zero-overtopping data in artificial neural network predictions. In Proceedings of the 5th Coastal Structures International Conference, Venice, Italy, pp. 1542-1551.

Mase H, Sakamoto M and Sakai T (1995) Neural network for stability analysis of rubble-mound breakwaters. Journal of Waterway, Port, Coastal, and Ocean Engineering, ASCE 121(6): 294-299.

Mase H, Takayama T and Kitano T (2001) Application of neural network method to breakwater problems. In Proceedings of Inaugural International Conference Port and Marine $R \& D$ and Technology, Singapore, pp. 393-398.

Mase H, Yasuda T and Mori N (2011) Real-time prediction of tsunami magnitudes in Osaka Bay, Japan, using an artificial neural network. Journal of Waterway, Port, Coastal, and Ocean Engineering, ASCE 137(5): 263-268.

Miles JW (1957) On the generation of surface waves by shear flows. Journal of Fluid Mechanics 3(2): 185-204.

Moeini MH, Etemad-Shahidi A and Chegini V (2010) Wave modeling and extreme value analysis off the northern coast of the Persian Gulf. Applied Ocean Research 32(2): 209-218.

Ozger M (2010) Significant wave height forecasting using wavelet fuzzy logic approach. Journal of Ocean Engineering 37(16): 1443-1451.

Phillips OM (1957) On the generation of waves by a turbulent wind. Journal of Fluid Mechanics 2(5): 417-445.

Phillips OM (1958) The equilibrium range in the spectrum of wind-generated waves. Journal of Fluid Mechanics 4(4): 426-434.

Rao S and Mandal S (2005) Hindcasting of storm waves using neural network. Journal of Ocean Engineering 32(5-6): 667684.

Reikard G (2009) Forecasting ocean wave energy: Tests of timeseries models. Journal of Ocean Engineering 36(5): 348-356.

Reikard G, Pinson P and Bidlot JR (2011) Forecasting ocean wave energy: The ECMWF wave model and time series methods. Journal of Ocean Engineering 38(10): 1089-1099. 
Reikard G and Rogers WE (2011) Forecasting ocean waves: Comparing a physics-based model with statistical models. Journal of Coastal Engineering 58(5): 409-416.

Rogers LL and Dowla FU (1994) Optimization of groundwater remediation using artificial neural networks with parallel solute transport modeling. Journal of Water Resources Research 30(2): 457-481.

Roulston MS, Ellepola J, Von Hardenberg J and Smith LA (2005) Forecasting wave height probabilities with numerical weather prediction models. Journal of Ocean Engineering 32(14-15): 1841-1863.

Saket A and Etemad-Shahidi A (2012) Wave energy potential along the northern coasts of the Gulf of Oman, Iran, Journal of Renewable Energy 40(1): 90-97.

The National Commission on Energy Policy (2004) Ending the Energy Stalemate: A Bipartisan Strategy to Meet America's Energy Challenges. The National Commission on Energy Policy, Washington, DC, USA.
Tsai CP, Lin C and Shen JN (2002) Neural network for wave forecasting among multi-stations. Journal of Ocean Engineering 29(13): 1683-1695.

Tseng CM, Jan CD, Wang JS and Wang CM (2007) Application of artificial neural networks in typhoon surge forecasting. Journal of Ocean Engineering 34(11): 17571768.

Woodcock F and Engel C (2005) Operational consensus forecasts. Journal of Weather Forecasting 20(1): 101-111. Woodcock F and Greenslade DJM (2006) Consensus of numerical forecasts of significant wave heights. Journal of Weather Forecasting 22(4): 792-803.

Young IR (1988) Parametric hurricane wave prediction model. Journal of Waterways Port Coastal and Ocean Engineering 114(5): 637-652.

Zamani A, Solomatine D, Azimian A and Heemink A (2008) Learning from data for wind-wave forecasting. Journal of Ocean Engineering 35(10): 953-962.

\section{WHAT DO YOU THINK?}

To discuss this paper, please email up to 500 words to the editor at journals@ice.org.uk. Your contribution will be forwarded to the author(s) for a reply and, if considered appropriate by the editorial panel, will be published as discussion in a future issue of the journal.

Proceedings journals rely entirely on contributions sent in by civil engineering professionals, academics and students. Papers should be 2000-5000 words long (briefing papers should be 1000-2000 words long), with adequate illustrations and references. You can submit your paper online via www.icevirtuallibrary.com/content/journals, where you will also find detailed author guidelines. 